\title{
Precipitation Behavior in Liesegang Systems under Microwave Irradiation
}

\author{
Yushin Kanazawa, Yusuke Asakuma \\ Department of Mechanical and Systems Engineering, University of Hyogo, Himeji, Japan \\ Email: asakuma@eng.u-hyogo.ac.jp
}

Received 12 November 2013; revised 12 December 2013; accepted 3 January 2014

Copyright (C) 2014 by authors and Scientific Research Publishing Inc.

This work is licensed under the Creative Commons Attribution International License (CC BY). http://creativecommons.org/licenses/by/4.0/

(c) (i) Open Access

\begin{abstract}
We studied precipitation patterns in a Liesegang system under microwave irradiation in order to investigate metal salt diffusion in an electrolyte gel. The salt species and microwave irradiation power were varied. Microwave irradiation induced periodic patterns of precipitation because polar molecules vibrate and rotate in an electromagnetic field. For example, the number of patterns increased with the irradiation power. Accordingly, microwave irradiation nonlinearly accelerated the diffusion of ionic molecules.
\end{abstract}

\section{Keywords}

Component, Microwave, Liesegang, Diffusion, Precipitation

\section{Introduction}

Liesegang phenomena, a function of diffusion and reaction conditions, form attractive and unique periodic stripe patterns. Such pattern formation frequently inspires microstructural design in materials science. Moreover, morphological pattern transitions between periodic precipitation and tree-like crystal aggregates are scientifically interesting [1] [2]. Liesegang phenomena usually manifest themselves when a concentrated salt solution diffuses through a gel that contains another electrolyte at a lower concentration. Diffusion and chemical reactions cause little precipiation of otherwise soluble salts in a periodic manner. The precipitation and redissolution reactions for a generic metal ion $\mathrm{M}^{2+}$ are as follows:

$$
\begin{gathered}
\mathrm{M}^{2+}(\mathrm{aq})+2 \mathrm{NH}_{4} \mathrm{OH}(\mathrm{aq}) \rightarrow 2 \mathrm{NH}_{4}^{+}(\mathrm{aq})+\mathrm{M}(\mathrm{OH})_{2}(\mathrm{~s}) \\
\mathrm{M}(\mathrm{OH})_{2}(\mathrm{~s})+6 \mathrm{NH}_{4}^{+}(\mathrm{aq}) \rightarrow \mathrm{M}\left(\mathrm{NH}_{3}\right)_{6}^{2+}(\mathrm{aq})+2 \mathrm{H}_{2} \mathrm{O}(\mathrm{l})+4 \mathrm{H}^{+}(\mathrm{aq})
\end{gathered}
$$

When $\mathrm{NH}_{4} \mathrm{OH}$ diffusion causes metal ions to precipitate in the form of $\mathrm{M}(\mathrm{OH})_{2}$, redissolution at the top of the 
pattern induces a Liesegang band.

Recent research indicates that spontaneous diffusion-related self-organization dynamics and irreversible reactions or precipitation systems based on Ostwald supersaturation theory explain Liesegang pattern formation [3]. However, nonlinearily hinders elaboration of the exact mechanism.

Microwave radiation may be helpful in this context. Microwave radiation has recently been a very active area of research due to the many advantages of nonthermal effects such as reaction promotion, nucleation induction, and diffusion facilitated by the molecular vibration of polar molecules [4] [5]. We hypothesized that the reaction and diffusion characteristics of a Liesegang system could be modulated or explained via various microwave properties. In addition, Liesegang phenomena may suggest a new application of microwave radiation and suitable operating conditions for highly functional inorganic nanomaterials. Salt and gel concentration [6], inner electrolyte species, and so on are essential for solving the diffusion challenge of Liesegang phenomena. In this study, we varied salt species and microwave output to understand the microwave effect. We used a microwave reactor equipped with an in situ observation system to analyze the dynamic growth behavior of the periodic pattern.

\section{Experimental}

To form a Liesegang pattern, we used a gel because it can prevent precipitate sedimentation and hydrodynamic turbulence. A salt was added to a prepared gelatin-based gel [7] [8]. In this study, gelatin and salt concentration were constant, and we used three salt species containing the same metal ion: $\mathrm{Co}\left(\mathrm{NO}_{3}\right)_{2}, \mathrm{CoCl}_{2}$, and $\mathrm{CoSO}_{4}$ (Table 1). These salts were selected because counterion species is a major controlling factor in pattern formation. The counterion modulates the solubility, diffusion coefficient, and dielectric constant of each salt, which is a function of microwave adsorption. We first heated a solution (i.e., gel and salt) to $90^{\circ} \mathrm{C}$. We then poured the solution into a glass test tube $(\varphi: 13 \mathrm{~mm}$; height: $100 \mathrm{~mm}$; volume: $5 \mathrm{~mL})$ and gradually cooled it to room temperature to impart a homogeneous gelatin network structure. Temperature is the most important factor for pattern formation; we used two different methods, microwave irradiation (MW) and conventional heating (oil bath, $\mathrm{OB}$ ) for maintaining solution temperature. After we poured $2 \mathrm{~mL}$ of a $28 \%$ ammonium solution at the gel surface, we covered it with a silicon rubber lid. Ammonium salt precipitates via ammonium ion diffusion into the gel, and Liesegang stripe-pattern formation starts from the top surface to the bottom of the tube. We measured the stripe number and length for the two heating methods.

\subsection{Microwave Heating}

Figure 1 shows a tube-guide microwave reactor (Shikoku Instrumentation), which is specially designed for preventing microwave leakage and equipped with a microscope camera (Sigma Koki, model SK-TC202USBAT) for in situ observation [9] [10]. We hung a test tube containing the solution by a thread at the center of the reactor. Immediately after pouring the ammonium solution onto the gel surface, we initiated microwave irradiation for $30 \mathrm{~min}$. Because the stripe pattern grows from the surface to the bottom, we gradually lifted up the test tube at a controlled speed to acquire photographs around the vertical stripe center, through the side of the reactor, with the fixed microscope. We measured the Liesegang pattern length via the pixel number between the top and bottom of the precipitation region, and we counted the stripes through the photographs every $5 \mathrm{~min}$. This approach enables dynamic evaluation of Liesegang pattern propagation with respect to microwave radiation. After $30 \mathrm{~min}$, we measured the final temperature with an optical fiber (Anritsu Meter) because the solution temperature increases under irradiation.

\subsection{Conventional Heating}

We used an oil bath to maintain the solution temperature. The bath temperature was increased over the course of

Table 1. Experimental conditions.

\begin{tabular}{cccc} 
& Gel conc. [w\%] & Salt conc. [mol/L] & MW output [W] \\
\hline $\mathrm{Co}\left(\mathrm{NO}_{3}\right)_{2}$ & 1.0 & 0.3 & $22,23,24$ \\
$\mathrm{CoCl}_{2}$ & 1.0 & 0.3 & $22,23,24$ \\
$\mathrm{CoSO}_{4}$ & 1.0 & 0.3 & $22,23,24$ \\
\hline
\end{tabular}


$30 \mathrm{~min}$ to the final temperature observed in the microwave experiment. We poured ammonium solution into the test tube immersed in the oil bath, and photographed the stripe pattern after $30 \mathrm{~min}$ with the microscope camera.

\section{Results and Discussions}

Figures 2-7 show photographs of the stripe pattern near the gel surface for each salt under MW or OB conditions after $30 \mathrm{~min}$. The experiment involves precipitation after the salt concentration in the gel exceeds the critical values (i.e., the solubility due to ammonium ion diffusion). We observed a stripe pattern in the case of $\mathrm{Co}\left(\mathrm{NO}_{3}\right)_{2}$

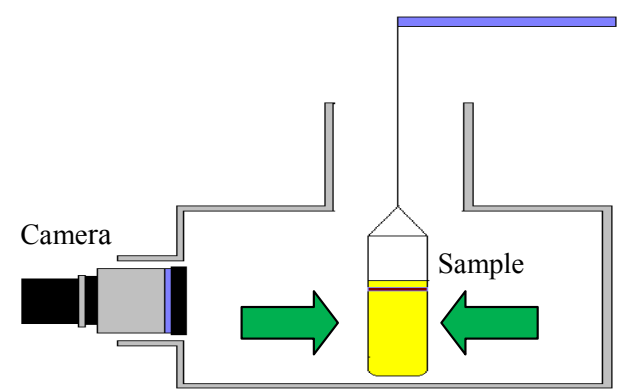

(a) Side view

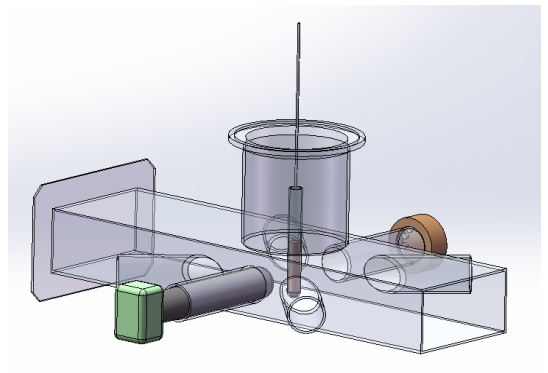

(b) $3 \mathrm{D}$ view

Figure 1. Microwave reactor.

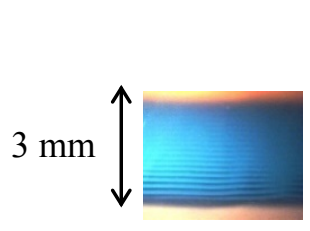

(a) $22 \mathrm{~W}$

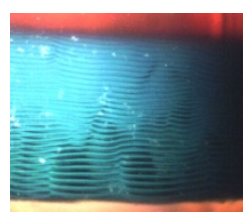

(b) $23 \mathrm{~W}$

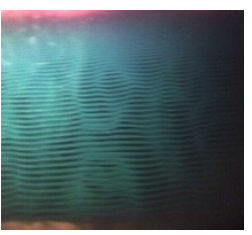

(c) $24 \mathrm{~W}$

Figure 2. $\mathrm{Co}\left(\mathrm{NO}_{3}\right)_{2}$ stripe pattern under MW.

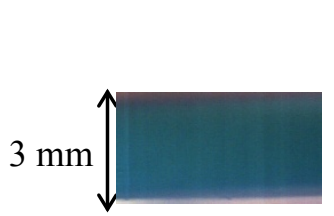

(a) $27^{\circ} \mathrm{C}$

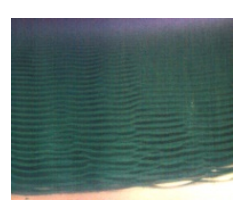

(b) $63^{\circ} \mathrm{C}$

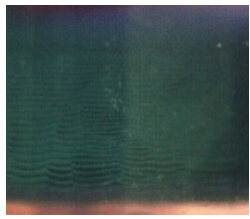

(c) $72^{\circ} \mathrm{C}$

Figure 3. $\mathrm{Co}\left(\mathrm{NO}_{3}\right)_{2}$ stripe pattern in $\mathrm{OB}$.

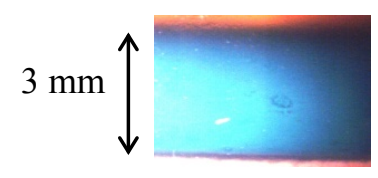

(a) $22 \mathrm{~W}$

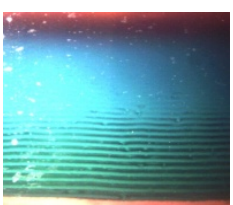

(b) $23 \mathrm{~W}$

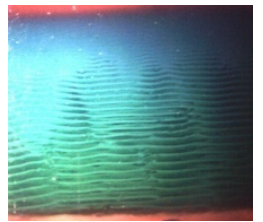

(c) $24 \mathrm{~W}$

Figure 4. $\mathrm{CoCl}_{2}$ stripe pattern under MW.

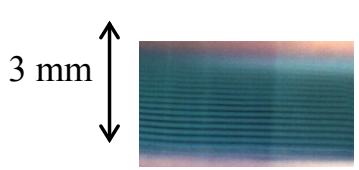

(a) $32^{\circ} \mathrm{C}$

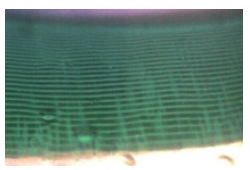

(b) $60^{\circ} \mathrm{C}$

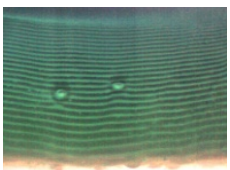

(c) $65^{\circ} \mathrm{C}$

Figure 5. $\mathrm{CoCl}_{2}$ stripe pattern in $\mathrm{OB}$. 
and $\mathrm{CoCl}_{2}$. However, the pattern induced by $\mathrm{CoSO}_{4}$ was not clear; 30 min may be insufficient for stable precipitation because of its higher solubility. We did not observe an expected pattern transition (e.g., a tree-like pattern [1]) in this experiment, and the parallel stripe pattern remained even under microwave irradiation.

To aid in understanding the mechanism of stripe-pattern formation, Figures 8 and 9 plot the stripe number and length, respectively, in relation to reaction time. Filled and open symbols indicate MW and OB conditions,

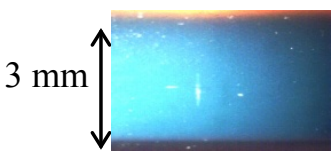

(a) $22 \mathrm{~W}$

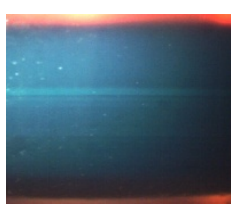

(b) $23 \mathrm{~W}$

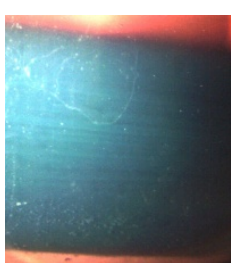

(c) $24 \mathrm{~W}$

Figure 6. $\mathrm{CoSO}_{4}$ stripe pattern under MW.

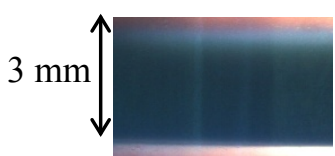

(a) $30^{\circ} \mathrm{C}$

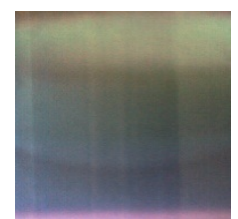

(b) $65^{\circ} \mathrm{C}$

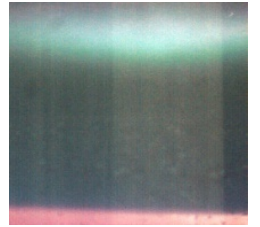

(c) $67^{\circ} \mathrm{C}$

Figure 7. $\mathrm{CoSO}_{4}$ stripe pattern in an $\mathrm{OB}$.

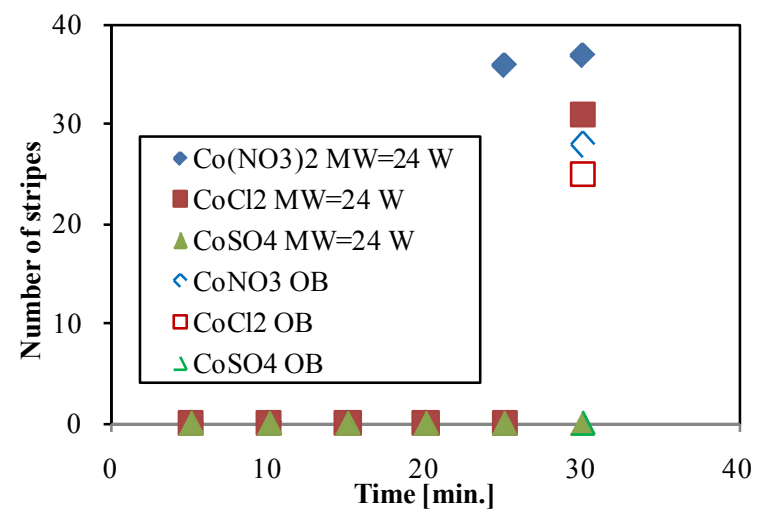

Figure 8. Stripe number versus time.

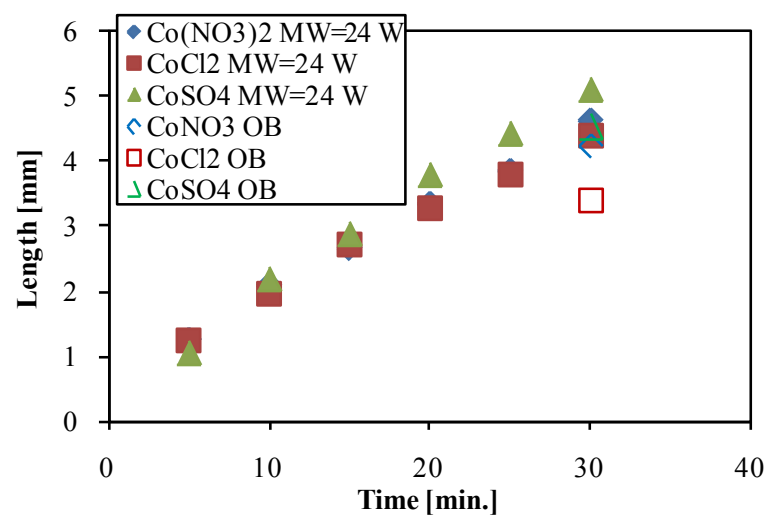

Figure 9. Liesegang pattern length versus time. 
respectively. Although precipitation starts just after contact with the ammonium solution, either the stripes do not immediately form or the camera resolution limit precludes sufficiently fast and precise image acquisition; accordingly, we assigned the initial number of stripes as 0 . We counted the number of stripes after approximately $25 \mathrm{~min}$. The stripe length linearly increased with reaction time (Figure 9). After $30 \mathrm{~min}$ of reaction time, nonthermal effects induced by microwave irradiation caused the stripe number and length to increase more rapidly for MW relative to OB. This is attributable to enhanced molecular diffusion and facilitated supersaturation. Molecular vibration induced by microwave irradiation accelerates ionic diffusion. Moreover, such vibration readily induces supersaturation of the precipitate. Consequently, cyclic periods of supersaturation, nucleation, and depletion become faster. However, temperature must be carefully controlled to modulate such cycling.

Figure 10 and Figure 11 show an almost linear relation of stripe number and length, after $30 \mathrm{~min}$ of irradiation, with respect to microwave power for $\mathrm{Co}\left(\mathrm{NO}_{3}\right)_{2}$ and $\mathrm{CoCl}_{2}$. MW imparted a greater effect than $\mathrm{OB}$. Consequently, microwave irradiation more effectively induced precipitation via supersaturation. Strip pattern formation did not proceed readily for $\mathrm{CoSO}_{4}$, even at a higher microwave irradiation power.

\section{Conclusion}

To understand the mechanisms of precipitation and diffusion in Liesegang patterns, experiments varying the salt species and microwave power were conducted in an oil bath and microwave reactor equipped with in situ observation system. Stripe length and number increased more quickly with respect to time under microwave irradiation than oil bath heating, and also increased with respect to microwave irradiation power. We explained these findings in the context of nonthermal effects (i.e., higher molecular diffusion and facilitated supersaturation) that are accelerated by radiation-induced molecular vibration. Microwave irradiation can modulate the diffusion and

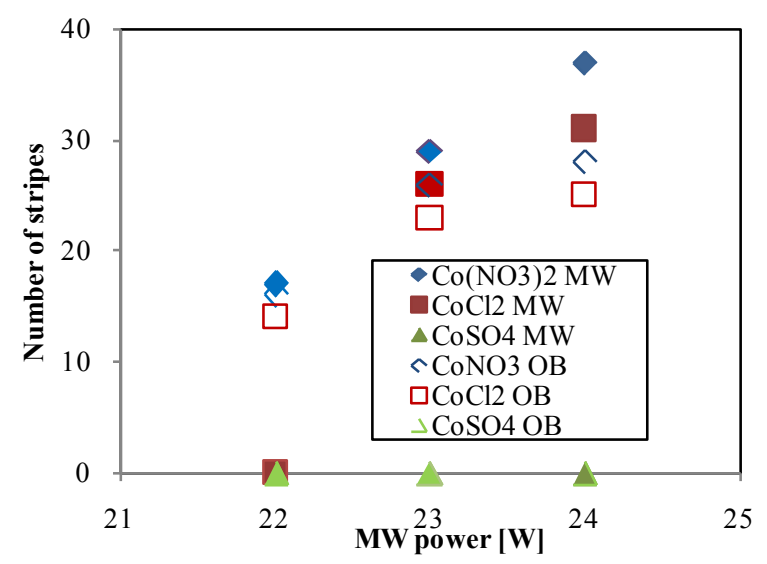

Figure 10. Stripe number versus MW power

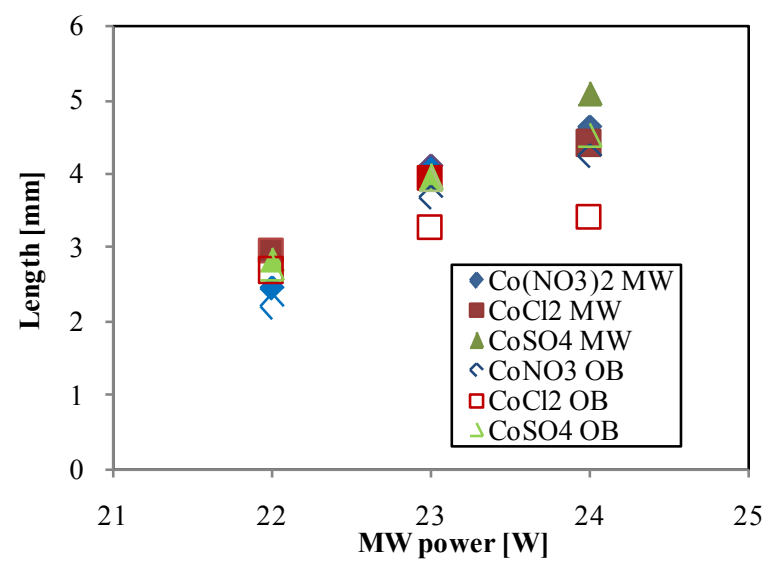

Figure 11. Liesegang pattern length versus MW power. 
manifestation of Leisegang patterns, and may be a useful tool in other fine-scale, nonequilibrium self-organization processes that involve precipitation and nonlinearity.

\section{References}

[1] Lagzi, I. and Ueyama, D. (2009) Pattern Transition between Periodic Liesegang Pattern and Crystal Growth Regime in Reaction-Diffusion Systems. Chemical Physics Letters, 468, 188-192. http://dx.doi.org/10.1016/j.cplett.2008.12.020

[2] Toramaru, A., Harada, T. and Okamura, T. (2003) Experimental Pattern Transitions in a Liesegang System. Physica D, 183, 133-140. http://dx.doi.org/10.1016/S0167-2789(03)00139-8

[3] Sultan, R., Ortoleva, P., DePasquale, F. and Tartaglia, P. (1990) Bifurcation of the Ostwald-Liesegang SupersaturationNucleation-Depletion Cycle. Earth-Science Reviews, 29, 163-173. http://dx.doi.org/10.1016/0012-8252(0)90034-S

[4] Menke, Y., Chiaretta, D., Milanese, D. and Ferraris, M. (2006) Microwave Assisted Diffusion of Au-Nanoclusters in Vitreous Silica. Journal of Non-Crystalline Solids, 352, 2526-2531. http://dx.doi.org/10.1016/j.jnoncrysol.2006.01.094

[5] Clemente, R.R. and Morales, J.G. (1996) Microwave Precipitation of CaCO3 from Homogeneous Solutions. Journal of Crystal Growth, 169, 339-346. http://dx.doi.org/10.1016/S0022-0248(96)00389-2

[6] Kanazawa, Y. and Asakuma, Y. (2013) Diffusion and Reaction Behaviors in Liesegang System under Microwave Radiation. World Confresss of Chemical Engineering.

[7] Das, I., Singh, P., Agrawal, N.R. and Rastogi, R.P. (1997) Liesegang Ring Type Structures and Bifurcation in Solid-Vapor and Liquid Phase Reactions between Cobalt Nitrate and Ammonium Hydroxide. Journal of Colloid and Interface Science, 192, 420-431. http://dx.doi.org/10.1006/jcis.1997.4922

[8] Msharrafieh, M. and Sultan, R. (2006) Dynamics of a Complex Diffusion-Precipitation-Re-Dissolution Liesegang pattern. Chemical Physics Letters, 421, 221-226. http://dx.doi.org/10.1016/j.cplett.2006.01.054

[9] Asakuma, Y., Kobayashi, K., Maeda, K. and Fukui, K. (2011) In-Situ Observation of Nano-Particle Behavior under Microwave Irradiation. Chemeca 2011, 008 .

[10] Asakuma, Y. and Koh, Y. (2013) Convection and Phase Separation Behavior of Binary Mixutre under Microwave Radiation. 8th World Conference on Experimental Heat Transfer, Fluid Mechanics, and Thermodynamics. 